\title{
Investigation of an imported case of Middle East Respiratory Syndrome Coronavirus (MERS-CoV) infection in Florence, Italy, May to June 2013
}

S Puzelli (simona.puzelli@iss.it) ${ }^{1}$, A Azzi ${ }^{2}$, M G Santini ${ }^{3}$, A Di Martino ${ }^{1}$, M Facchini $^{1}$, M R Castrucci ${ }^{1}$, M Meola $^{1}$, R Arvia ${ }^{2}$, C Corcioli $^{2}$,

F Pierucci ${ }^{2}$, S Baretti $^{3}$, A Bartoloni ${ }^{4}$, D Bartolozzi ${ }^{5}$, M de Martino ${ }^{6}$, L Galli ${ }^{6}$, M G Pompa $^{7}$, G Rezza $^{1}$, E Balocchini ${ }^{8}$, I Donatelli ${ }^{1}$

1. National Influenza Centre, Department of Infectious, Parasitic and Immune-mediated Diseases, Istituto Superiore Sanità (ISS), Rome, Italy

2. Regional reference laboratory for Influenza, Department of Experimental and Clinical Medicine, University of Florence, Italy

3. Local health district (ASL 10), Florence, Italy

4. Infectious and Tropical Diseases Unit, Careggi Hospital, Florence, Italy

5. Infectious Diseases Unit, Careggi Hospital, Florence, Italy

6. Department of Health Sciences, University of Florence, Anna Meyer University Children's Hospital, Florence, Italy

7. Ministry of Health, Rome, Italy

8. Tuscany Regional Health Authority, Florence, Italy

Citation style for this article:

Puzelli S, Azzi A, Santini MG, Di Martino A, Facchini M, Castrucci MR, Meola M, Arvia R, Corcioli F, Pierucci F, Baretti S, Bartoloni A, Bartolozzi D, de Martino M, Galli L, Pompa MG, Rezza G, Balocchini E, Donatelli I. Investigation of an imported case of Middle East Respiratory Syndrome Coronavirus (MERS-CoV) infection in Florence, Italy, May to June 2013. Euro Surveill. 2013;18(34):pii=20564. Available online: http://www.eurosurveillance.org/ViewArticle.aspx?Articleld=20564

Article submitted on 30 July 2013 / published on 22 August 2013

On 31 May 2013, the first case of Middle East Respiratory Syndrome Coronavirus (MERS-CoV) infection in Italy was laboratory confirmed in a previously healthy adult man, who developed pneumonia with moderate respiratory distress after returning from a holiday in Jordan. Two secondary cases were identified through contact tracing, among family members and colleagues who had not previously travelled abroad. Both secondary cases developed mild illness. All three patients recovered fully.

On 31 May 2013, the National Influenza Centre at the Istituto Superiore Sanità (NIC-ISS) in Rome, Italy, confirmed the first case of Middle East Respiratory Syndrome Coronavirus (MERS-CoV) infection in a patient, hospitalised in Florence (Tuscany region), Italy, who had just spent a vacation in Amman, Jordan. Two secondary cases of MERS-CoV were subsequently detected among close contacts. We here report the public health investigation carried out and the identification and follow-up of the three patients' contacts.

\section{Index case}

The index case was a previously healthy man in his mid-40s who had returned to Florence on 25 May 2013, following a 40-day holiday in Jordan (Figure). The patient developed influenza-like symptoms the previous day, while in Jordan, and was symptomatic on the flight back to Italy and while back at work in a hotel on 27 May. On 28 May, because of worsening symptoms, he visited the emergency room of a local hospital (Hospital A) in Florence and was admitted later the same day to the Infectious and Tropical Diseases Unit of a second hospital (Hospital B), in the same city. His symptoms at that time were fever $\left(38^{\circ} \mathrm{C}\right)$, cough and difficult breathing. A chest radiograph revealed signs of pneumonia, with bilateral lung infiltrates. The following day, testing for MERS-CoV was carried out (real-time polymerase chain reaction (PCR) to detect the regions upstream of the $E$ gene (upE region)) on upper respiratory samples (nasopharyngeal swabs) at the Regional reference laboratory for Influenza at the University of Florence and MERS-CoV infection was diagnosed. This result was confirmed by the National Influenza Centre [1].

On 29 May, as soon as the clinicians began to suspect a MERS-CoV infection, the staff of Hospital B complied with all infection control procedures, according to the Health Protection Agency (HPA) (now Public Health England) infection control advice for suspected or confirmed novel coronavirus cases [2]. In particular, the patient was isolated in a negative-pressure room and staff wore protective clothing and performed hand hygiene. Attempts were made at the Regional reference laboratory for Influenza in Florence to isolate the virus in Vero cells, but were unsuccessful.

\section{Identification of close contacts}

According to a standard definition of 'close contact' [3], 115 contacts of this patient were identified and placed under surveillance: 90 in the healthcare setting (14 healthcare workers (HCWs) in Hospital A, two HCWs of the local health district (ASL 10) of Florence, $28 \mathrm{HCWs}$ of Hospital $B$, one patient who shared the same hospital room (before the index case was placed in isolation), five cleaners of Hospital B, who worked in the room of the index case (before he was placed in isolation) and three ambulance operators); in addition, the surveillance included 37 patients who attended the emergency room in Hospital $A$ at the same time of the index case); four family members; nine from the aeroplane 


\section{FIGURE}

Timeline of three cases of Middle East Respiratory Syndrome Coronavirus (MERS-CoV) infection, Italy, 24 May-6 June 2013

\begin{tabular}{|c|c|c|c|}
\hline Index case & Day & Case 2 & Case 3 \\
\hline & May & & \\
\hline Symptom onset & 24 & & \\
\hline \multirow{3}{*}{ Return from Jordan to Italy } & May & & \\
\hline & 25 & & \\
\hline & $\begin{array}{c}\text { May } \\
26\end{array}$ & $\begin{array}{l}\text { Contact with } \\
\text { index case }\end{array}$ & \\
\hline Back to work & $\begin{array}{c}\text { May } \\
27\end{array}$ & & $\begin{array}{l}\text { Contact with } \\
\text { index case }\end{array}$ \\
\hline $\begin{array}{l}\text { - Attended Hospital A } \\
\text { emergency room } \\
\text { - Admitted to Hospital B } \\
\text { - Pneumonia diagnosed }\end{array}$ & $\begin{array}{c}\text { May } \\
28\end{array}$ & & \\
\hline \multirow[t]{8}{*}{$\begin{array}{l}\text { NPS collected and } \\
\text { tested for MERS-CoV }\end{array}$} & $\begin{array}{c}\text { May } \\
29\end{array}$ & Symptom onset & \\
\hline & $\begin{array}{l}\text { May } \\
30\end{array}$ & & \\
\hline & $\begin{array}{c}\text { May } \\
31\end{array}$ & $\begin{array}{l}\text { Admitted to } \\
\text { Hospital C }\end{array}$ & Symptom onset \\
\hline & $\begin{array}{c}\text { June } \\
1\end{array}$ & $\begin{array}{l}\text { NPS tested for } \\
\text { MERS-CoV }\end{array}$ & $\begin{array}{l}\text { - Admitted to Hospital B } \\
\text { - NPS collected and } \\
\text { tested for MERS-CoV }\end{array}$ \\
\hline & $\begin{array}{c}\text { June } \\
2\end{array}$ & & \\
\hline & $\begin{array}{c}\text { June } \\
3\end{array}$ & & \\
\hline & $\begin{array}{c}\text { June } \\
4\end{array}$ & & \\
\hline & $\begin{array}{c}\text { June } \\
5\end{array}$ & Discharged & \\
\hline Discharged & $\begin{array}{c}\text { June } \\
6\end{array}$ & & Discharged \\
\hline
\end{tabular}

NPS: nasopharyngeal swab. (the names of the passengers who were on the same return flight of the index case, with an assigned seat in the same row and in the two rows in front and behind him, were easily obtained but the exact position of these contacts on the plane was difficult to assess as some passengers could have changed their assigned seats); and 12 at the patient's place of work.) However, it must be underlined that, although particular attention was given to people who had had prolonged faceto-face contact with the index case (duration of at least 15 minutes within one metre from the confirmed case), some of the above 115 individuals placed under clinical surveillance, mainly from the healthcare setting, may have had a lesser degree of contact with him or were already wearing personal protective equipment at the time of contact.

\section{Cases 2 and 3}

On 29 May, the index case's relation (Case 2) aged about a year and a half developed a mild febrile illness (Figure). She had been in close contact with the index case on May 26, when the man spent all the day with her and her family, staying in the same room. As she was under surveillance, she was admitted to a children's hospital (Hospital C) in Florence, on 31 May and a nasopharyngeal swab was taken. This tested positive for MERS-CoV, by real-time PCR for the upE region, the following day. Five family members of the child underwent clinical surveillance.

On 31 May, a female co-worker of the index case (Case 3 ), in her early 40s, who shared the same office with the index case on 27 May, developed influenza-like illness (fever ( $37.5^{\circ} \mathrm{C}$ ) and cough) (Figure). She was admitted to the Infectious Diseases Unit of Hospital $B$ in Florence on 1 June and a nasopharyngeal swab tested positive for MERS-CoV, by real-time PCR for the upE region, the same day. Her five family members (husband, three sons and her father) were also placed under clinical surveillance. A further three close contacts (two friends and a family general practitioner) were identified: these eight contacts plus 16 work colleagues were monitored clinically, bringing the total number of Case 3's contacts placed under surveillance to 24 .

As for the index case, the nasopharyngeal swabs of Cases 2 and 3 were tested for MERS-CoV by real time PCR for the upE gene [1]. According to guidance documents of the World Health Organization (WHO) [4], these laboratory results were interpreted as 'presumptive' evidence of MERS-CoV infection in both cases. The final classification as confirmed cases was given on the basis of laboratory data combined with clinical/ epidemiological information available.

\section{Case definition and clinical surveillance of contacts}

In Italy, a possible case of MERS-CoV infection is defined as follows: 
- any patient with an acute respiratory infection, which may include history of fever $\left(\geq 38{ }^{\circ} \mathrm{C}\right)$ and cough and indications of pulmonary parenchymal disease (e.g. pneumonia or acute respiratory distress syndrome (ARDS)), AND

- whose illness cannot be explained by the presence of other infections, AND

- who had a history of travel to or residence in affected areas (in the Middle East), during the 10 days before symptom onset, OR

- having had close contact, during the 10 days before symptom onset, with a symptomatic confirmed case of MERS-CoV infection.

On the basis of WHO and ECDC guidance documents $[5,6]$, a probable case of MERS-CoV infection is defined as follows:

- a person with a febrile acute respiratory illness with clinical, radiological or histopathological evidence of pulmonary parenchymal disease (e.g. pneumonia or ARDS), AND

- for whom MERS-CoV infection has not been laboratory confirmed, AND

- who has no direct epidemiological link to a confirmed MERS-CoV case.

A confirmed case is defined as a person with laboratory confirmation of MERS-CoV infection $[5,6]$.

According to national guidelines [7], for each possible case, clinical samples from the upper respiratory tract (nasopharyngeal swabs), as well as lower respiratory specimens (sputum or bronchoalveolar lavage fluid, when possible), have to be collected and tested for MERS-CoV in an initial screen by the regional reference laboratory; positive results have to be confirmed by the National Influenza Centre at ISS.

As soon as the index case was suspected to be infected with MERS-CoV, exposed individuals were identified through contact tracing and a clinical surveillance protocol was followed. All contacts were followed up during a 10-day period (i.e. the maximum incubation period, according to the knowledge of the disease at the time of the investigation described in this report) [5] after their last contact with the index case, to check if symptoms appeared. Particular attention was given to people who had had prolonged face-to-face contact with the index case (duration of at least 15 minutes within one metre from the confirmed case).

\section{Discussion}

As of 1 August 2013, 94 laboratory-confirmed cases of MERS-CoV infection have been reported worldwide since the first detection of this novel virus in Saudi Arabia in 2012, including 46 deaths [8].

In this report, we present the investigation of the first case of MERS-CoV diagnosed in Italy and also present evidence of limited person-to-person transmission of
MERS-CoV, to two people who had close contact with the symptomatic index case when he was back in Italy and who had not previously travelled abroad. Both secondary cases were classified as confirmed on the basis of a combination of clinical (influenza-like illness), epidemiological (close contact with the index case) and laboratory data, according to WHO guidelines [4]. Nasopharyngeal swabs of both secondary cases tested positive only in the screening assay (real-time PCR to detect the regions upstream of the $\mathrm{E}$ gene), probably due to the known limitations when using upper respiratory tract specimens [5,9]. Although required [7], lower respiratory tract specimens were not available.

It must be underlined that the index case was a previously healthy middle-age man, who developed fever and respiratory symptoms on 24 May, i.e. the day before his travel from Jordan to Italy. For the two secondary cases, the putative incubation time (i.e. days from putative exposure to symptom onset) was 3-4 days, according to data already reported $[10,11]$. The incubation period was somewhat shorter than that found for the Severe Acute Respiratory Syndrome (SARS)-coronavirus infection [12].

All three patients, including the index case who developed pneumonia, fully recovered in less than two weeks after symptom onset, unlike most of the MERSCoV severe cases reported [10,11]. Nevertheless, it should be stressed that none of the three patients had underlying clinical conditions. In this regard, it is also important to highlight recent findings [10] that suggested the disease is milder in people who were identified through contact tracing, compared with that seen in those presenting with symptoms.

None of the other 144 contacts monitored ( 115 for the index case, 5 for Case 2 and 24 for Case 3) developed fever or other symptoms suggestive of an acute respiratory illness after 10 days' follow-up. Respiratory specimens have been collected from 70 of the contacts and have tested negative for MERS-CoV.

As useful additional information can be obtained from serological investigations, we will analyse sera collected from the three cases. Furthermore, although rapid contact tracing was undertaken, identification and follow-up of a larger number of contacts and the collection of serum samples would be of great value, to better determine the potential presence of subclinical infections. Notably, an increasing proportion of people with asymptomatic infection have been recently reported $[9,13]$, through contact tracing among close contacts of cases. 


\section{Acknowledgements}

The authors are grateful to Tiziana Grisetti for editing the manuscript.

\section{Conflict of interest}

None declared.

\section{Authors' contributions}

Simona Puzelli: coordinated the laboratory investigation for case confirmation. Simona Puzelli, Maria Rita Castrucci and Isabella Donatelli: wrote the manuscript. Alberta Azzi: supervised and coordinated the initial laboratory investigation on the three cases and contacts and was responsible for testing and interpretation of results from respiratory samples. Maria Grazia Santini and Simonetta Baretti: coordinated the contact surveillance. Angela Di Martino, Marzia Facchini and Monica Meola: performed laboratory testing for case confirmation. Rosaria Arvia, Fabiana Corcioli and Federica Pierucci: performed the initial laboratory testing on patients and contacts. Alessandro Bartoloni: provided data on the in dex case. Dario Bartolozzi: provided data on the co-worker of the index case (Case 3). Maurizio de Martino and Luisa Galli: cared for the child (Case 2). Giovanni Rezza, Isabella Donatelli and Maria Grazia Pompa: supervised the investigation and coordinated the relationships with health authority at national and international level. Emanuela Balocchini: supervised and coordinated the investigation at regional level. All co-authors: provided comments and revised the manuscript.

\section{References}

1. Corman VM, Eckerle I, Bleicker T, Zaki A, Landt O, EschbachBludau M, et al. Detection of a novel human coronavirus by real-time reverse-transcription polymerase chain reaction. Euro Surveill. 2012;17(39):pii=20285. Available from: http:// www.eurosurveillance.org/ViewArticle.aspx?Articleld $=20285$

2. Public Health England (PHE). Infection control advice. Middle East respiratory syndrome coronavirus. Infection control advice: possible or confirmed MERS-CoV cases: Version 2.0, 28 June 2013. London: PHE; 2013. Available from: http://www.hpa. org.uk/webc/HPAwebFile/HPAweb_C/1317136232722

3. The Health Protection Agency (HPA) UK Novel Coronavirus Investigation team. Evidence of person-to-person transmission within a family cluster of novel coronavirus infections, United Kingdom, February 2013. Euro Surveill. 2013;18(11): pii =20427. Available from: http://www.eurosurveillance.org/ViewArticle. aspx?Articleld $=20427$

4. World Health Organization (WHO). Laboratory testing for novel coronavirus. Interim recommendations. 21 December 2012. Geneva: WHO; 2012. Available from: http://www.who.int/csr/ disease/coronavirus_infections/LaboratoryTestingNovelCorona virus_21Dec12.pdf

5. European Centre for Disease Prevention and Control (ECDC) Severe respiratory disease associated with Middle East respiratory syndrome coronavirus (MERS-CoV). 17 May 2013 Stockholm: ECDC; 17 May 2013. Available from: http://www. ecdc.europa.eu/en/publications/Publications/risk-assessmentmiddle-east-respiratory-syndrome-coronavirus-MERS-CoV-17may-2013.pdf

6. World Health Organization (WHO). Revised interim case definition for reporting to WHO - Middle East respiratory syndrome coronavirus (MERS-CoV). Interim case definition as of 19 February 2013. Geneva: WHO; 2013. Available from: http://www.who.int/csr/disease/coronavirus_infections/case definition_19_02_2013/en/index.html

7. Ministero della Salute. Infezione da nuovo coronavirus. [New coronavirus infection]. Rome: Ministero della Salute; 16 May 2013. Circolare del Ministero della Salute (DGPRE/0011311-P-16/05/2013). Italian. Available from: http:// www.trovanorme.salute.gov.it/renderNormsanPdf?anno=0\&co $\mathrm{dLeg}=46038 \&$ parte $=1 \% 20$ \& serie $=$

8. ProMED-mail. MERS-CoV - Eastern Mediterranean (51): Saudi Arabia, WHO, Request for information. Archive Number 20130801.1857286. 1 August 2013. Available from: http://www. promedmail.org/direct.php?id=20130801.1857286

9. European Centre for Disease Prevention and Control (ECDC). Severe respiratory disease associated with Middle East respiratory syndrome coronavirus (MERS-CoV), 6th update. 19 July 2013. Stockholm: ECDC; 2013. Available from: http:// www.ecdc.europa.eu/en/publications/Publications/RRA-ECDCMERS-CoV-Sixth-update.pdf

10. Assiri A, McGeer A, Perl TM, Price CS, Al Rabeeah AA, Cummings DAT, et al. Hospital outbreak of Middle East Respiratory Syndrome Coronavirus. N Engl J Med. 2013;369(5):407-16. http://dx.doi.org/10.1056/NEJMoa1306742 PMid:23782161

11. World Health Organization (WHO). Interim surveillance recommendations for human infection with Middle East respiratory syndrome coronavirus. As of 27 June 2013. Geneva: WHO; 2013. Available from: http:// www.who.int/csr/disease/coronavirus_infections/ InterimRevisedSurveillanceRecommendations nCoVinfection_27Jun13.pdf

12. Lipsitch M, Cohen T, Cooper B, Robins JM, Ma S, James L, et al. Transmission dynamics and control of severe acute respiratory syndrome. Science. 2003;300(5627):1966-70. http://dx.doi.org/10.1126/science.1086616 PMid:12766207 PMCid:PMC2760158

13. World Health Organization (WHO). MERS-CoV summary and literature update - as of 9 July 2013. Geneva: WHO; 2013. Available from: http://www.who.int/csr/disease/coronavirus_ infections/update_20130709/en/index.html 